\title{
Energy Management System Using Renewable Energy Sources
}

\author{
Shweta Doddamallappanavar' ${ }^{1}$, Deepa S Haveri' ${ }^{1}$, Asst. Prof. Chaitanya K Jambotkar ${ }^{2}$ \\ ${ }^{1}$ Student, ${ }^{2}$ Assistant Professor \\ Department of Electrical and Electronics Engineering, K.L.E.I.T, Hubli, Karnataka, India
}

\begin{abstract}
Energy usage index indicates the country's state of economy, growth and standard of living. But the rate at which the energy demands and prices are increasing, it may be difficult to get the correct rate of development. The result of the same is to enforce retarding action on the growth and industrialization programs of developing countries like India for the want of sufficient energy reserves. Energy management refers to efforts made to reduce energy consumption. Smart homes hold the potential for increasing energy efficiency, decreasing costs of energy use, decreasing the carbon footprint by including renewable resources. This article presents a discussion of state of the art in electricity management and conserving the renewable energy sources.
\end{abstract}

KEYWORDS: Renewable energy sources, Energy Management System, Smart system, Conserving energy

\section{INTRODUCTION}

Today's energy crisis becomes global problem for the world. We need to reduce the wastage of electricity in day to day life. But the consumption of electricity increases year to year as more home appliances are installed. So, today's the energy saving becomes first priority. Because of the limited fossil fuels, these generations have started the use of different ways of electricity generation like using the renewable energy sources. Solar, wind and water sources are easily available anywhere on earth. Renewable Energy Sources (RES) as an important approach to meeting rural energy needs, reducing pollution, and promoting economic development. A Smart Home is a house that uses new technologies to monitor the in-house temperature, outhouse climate changes, control and monitor the home appliances and communicates with the worldwide. Smart homes have the potential for increasing energy efficiency, decreasing costs of energy use, decreasing the carbon footprint by including renewable resources, and transforming the role of the occupant[1][2][3].This project proposes a novel model of smart homes for rural areas where reaching or $24 * 7$ power supply is one big question till date.

Energy can be managed through increased efficient energy use. It results in increased financial capital, environmental quality, national security, personal security and human comfort. In passive solar building design, windows, walls and floors are made to collect, store and distribute solar energy in the form of heat in the winter and reject solar heat in summer. This is called passive solar design or climatic design because unlike active solar heating systems, it doesn't involve the use of mechanical and electrical devices. Responsibility for energy conservation fall between three Government departments: Department for Energy and Climate Change(DECC),The Department for Communities and Local Government(CLG), and The Department for Environment, Food and Rural Affairs(Defra).

The below table1 and table 2 represents the power production scenario in India.
Table 1 Sector wise production of electricity

\begin{tabular}{|c|c|c|}
\hline Sector & MW & Percentage \\
\hline State sector & $86,881.13$ & 41.51 \\
\hline Central sector & $62,373.63$ & 29.66 \\
\hline Private sector & $60,321.28$ & 28.83 \\
\hline Total & $2,09,276.04$ & 100.00 \\
\hline
\end{tabular}

Table 2 Resource wise production of electricity

\begin{tabular}{|c|c|c|}
\hline Fuel & MW & Percentage \\
\hline Thermal & $1,40,206.18$ & 66.99 \\
\hline Coal & $1,20,103.38$ & 57.38 \\
\hline Gas & $18,903.05$ & 9.03 \\
\hline Oil & $1,199.75$ & 0.57 \\
\hline Hydro & $39,291.40$ & 18.77 \\
\hline Nuclear & $4,780.00$ & 2.28 \\
\hline RES (MNRE) & $24,998.46$ & 11.94 \\
\hline Total & $2,09,276.04$ & 100.00 \\
\hline
\end{tabular}

II. Conservation of Electricity at various level A. Conservation at household level

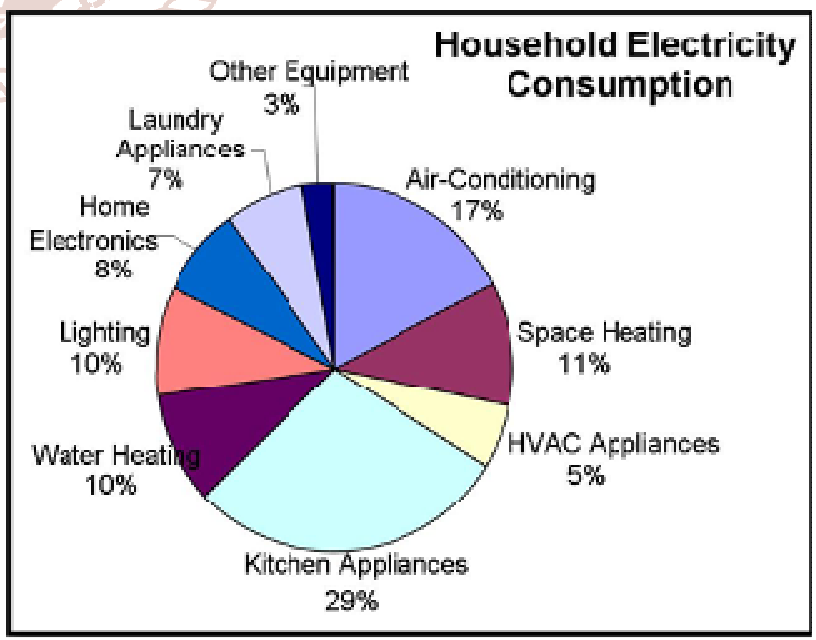

Fig. 1 Household Electricity Consumption

Refrigerator: It should be maintained at 37-40degree centigrade and freezer section at 50degree centigrade an avoid the opening of door frequently.

Microwave oven: Microwave ovens are better to use as they consume $50 \%$ less energy than the conventional ovens. 
Rearrange oven shelves before turning on the oven and do not peep into it. Every time the oven is opened the temperature Is lowered by 4-5degree centigrade.

Ironing: Ironing consumes approximately about 1000 watt energy. Hence it is better to iron clothes in bulk than one or two at a time.

Washing machine: It consumes $20 \%$ of the electricity. Cold water should be used while washing and rinsing as $90 \%$ of the energy consumed by machine is used to heat the water.

Lighting: Turn off the lights when not in use. Avoid using lights during day time. Use CFL in place of incandescent bulbs. A 23 watt CFL can replace 90 or 100 watt bulb. Do not keep TV, computer, tape recorder, music system in stand by mode. IT saves up to 70kilowatt hour per year.

\section{B. Conservation at Industrial level}

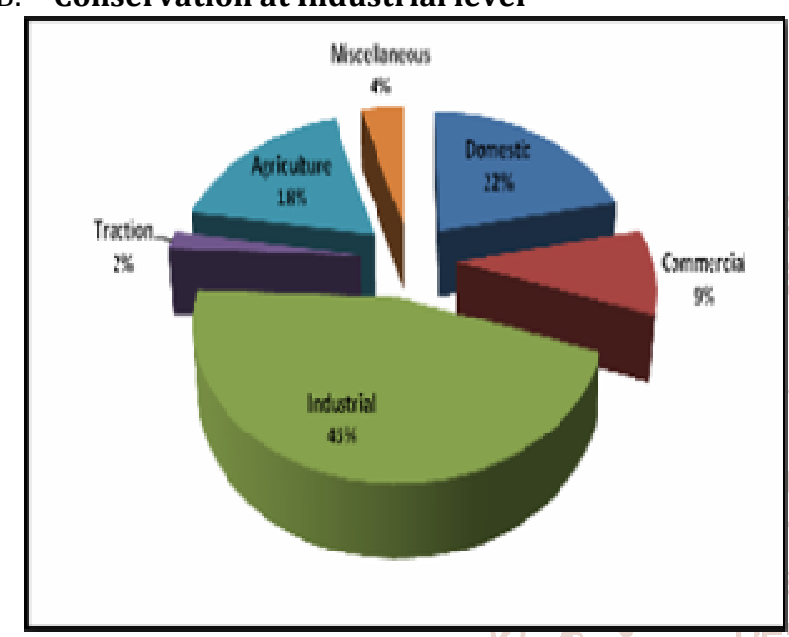

Fig. 2 Industrial Electricity Consumption

Auditing: Regular monitoring and audit of energy consuming results in energy conservation.

Process modification: It means old and more energy consuming processes by the new energy efficient processes.

Energy loss reduction: A lot of energy is wasted everyday. It can be reduced by following certain steps like, thermal insulation of fuel tanks can be done, electrical tracing of liquid fuel lines instead of conventional steam heating.

\section{Electricity Conservation in Transportation}

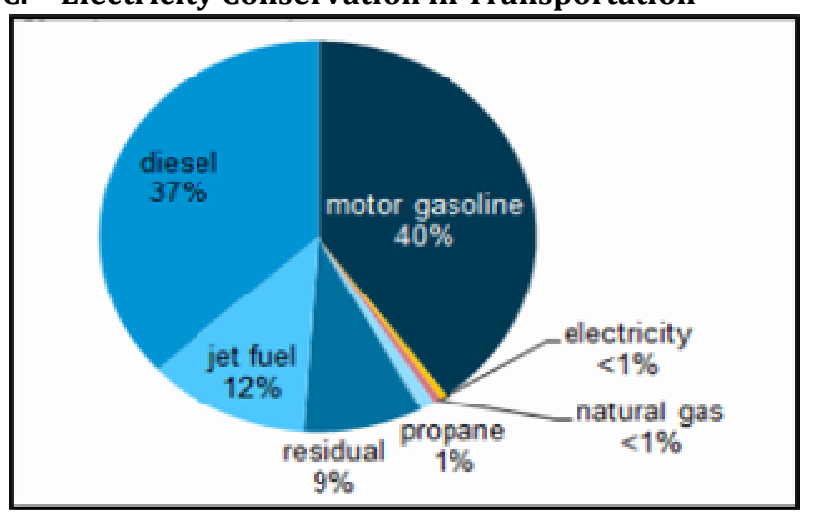

Fig. 3 Electricity conservation in Transportation

Approximately $65 \%$ of fuel is consumed by gasoline powered vehicles, $20 \%$ by diesel powered transport. Air transport consumes remaining $15 \%$ of the fuel. Use public transport as much as possible instead of own vehicles. Car speed should be maintained as far as possible 50 to $60 \mathrm{~km} / \mathrm{hr}$. Do not choke unless necessary, when choke is used, put it off as soon as engine is warmed up. If there is a starting trouble press clutch to start the engine.

\section{Renewable Energy Sources}

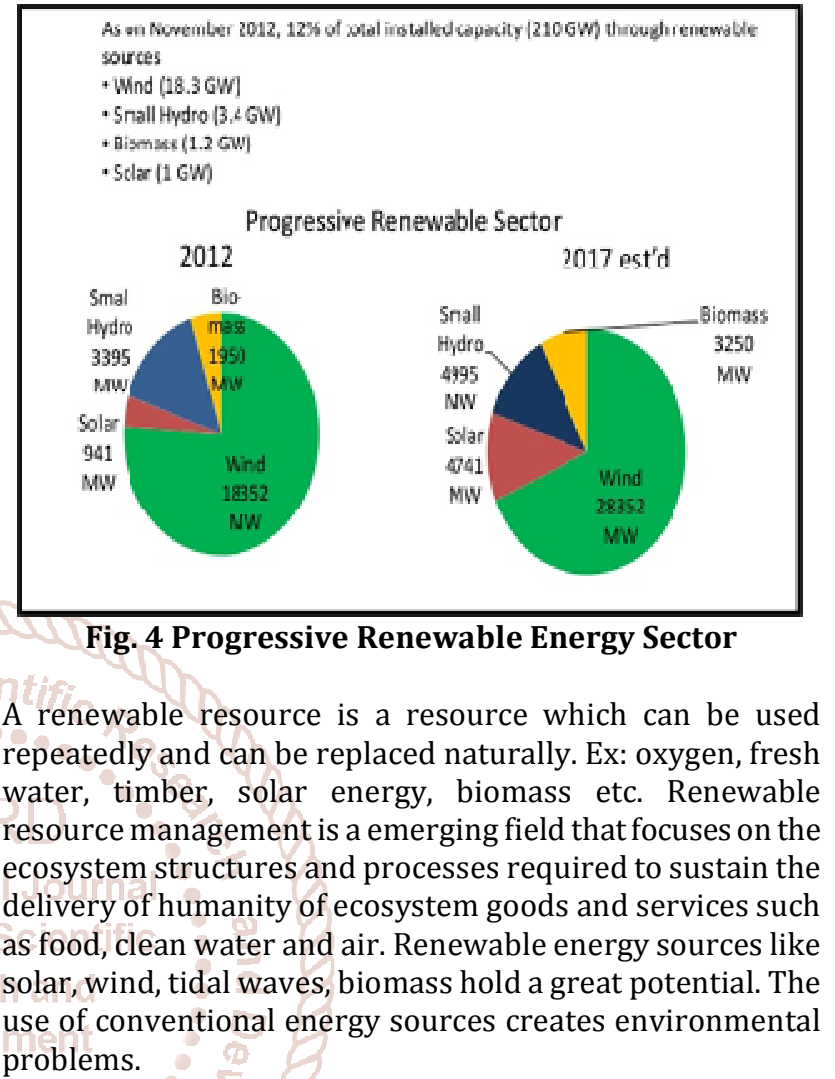
problems.

The increased use of fossil fuels increases carbon emission and quickens global climate change. Demonstration of projects involving the introduction of renewable solar technologies at the community level like the solar pumps, for water purification and irrigation of lawns, playgrounds as well as solar energy for cooking and heating should be promoted. Environment friendly public transport system should be promoted to reduce the use of individual motorized transport. It will help in reducing $\mathrm{CO}_{2}$ emissions.

On-going concerns about climate change have made renewable energy sources an important component of the world energy consumption portfolio. Renewable energy technologies could reduce carbon dioxide emissions by replacing fossil fuels in the power generation industry and the transportation sector. Due to negative and irreversible externalities in conventional energy production, it is necessary to develop and promote renewable energy supply technologies. Power generation using renewable energy sources should be increased in order to decrease the unit cost of energy and to make them compatible with a competitive alternative to the conventional energy sources. Two main solutions may be implemented to reduce $\mathrm{CO} 2$ emissions and to overcome the problem of climate change: replacing fossil fuels with renewable energy sources as much as possible and enhancing energy efficiency regardless of type. In this review, we considered hydro, wind, solar and geothermal sources, because of their significant contribution to power generated by renewable sources. 
Renewable energy production and supply is continuously increasing on the global level. Following the drastic increase in oil price and its impacts on both coal and gas prices, a large amount of investment has been made over recent years in renewable energy. These advancements in technology have enabled countries to produce renewable energy in larger quantities and more cost effectively. Due to negative and irreversible externalities associated with conventional energy extraction and consumption, it is necessary to promote and develop renewable energy supply and consumption. The IEA forecasts positive developments in renewable energy sources. They act as substitutes for fossil fuels and reduce emissions.

In the short term, some renewable technologies may not be comparable to conventional fuels in the scope of production costs and transmission, but they could be comparable if we consider their associated positive externalities, such as their environmental and social effects. Also, it should be noted that economies of scale could play a key role in reducing the unit cost of production. Transmission and distribution costs and technologies do not differ much among the conventional and renewable energy sources. In this review we have presented detailed facts about the main renewable energy supply technology developments, including hydro, wind, solar, and geothermal in detail and other sources such as biomass, ocean waves and tides in brevity. The emphasis has been on current production capacity and the estimated capacity, as well as development costs which are sunk. We have also presented empirical findings from comparative studies of alternative energy technologies. Hydro power is the largest renewable energy source for power generation around the world.

Despite its large energy generation contribution, its development is difficult due to a high initial fixed investment cost and environmental and population relocation costs. Hydro power is attractive due to a combined supply of water for agriculture, household, recreation and industrial use. Additionally, it can store water and energy that can be used for both base and peak load power generations. The availability of funding, political and market risks, resource allocation priorities and local environmental concerns are considered to be barriers to the development of hydro power capacity. The installed wind power capacity has also been increasing, especially in countries like China, the US, Germany and Denmark.

Advantages of wind power plants include the installation as turnkey contracts within a short period, a lower investment compared to nuclear and hydroelectric plants, economies of mass production, an absence of fuel costs and low operation and maintenance costs. The problems associated with the use of wind power include intermittency of wind energy and an added cost for power transmission to users. Generation cost is dependent on location, feasibility and the minimum required speed for wind turbines. China has developed its own solar power capacity, decreasing the cost of generation due to the availability of cheap labor and public subsidies. Another source of the reduced costs is in advances and the high efficiency in concentrated solar power technologies in the US. The negative effects include land, material and chemical use and impacts on buildings' esthetics. The performance is dependent on location.
Geothermal energy has been used throughout history for bathing, heating and cooking. The geothermal gradient and permeability of rocks determines its economic implementation feasibility. Unlike wind and solar power, geothermal is continuously available through the year, although technology has some negative environmental effects. Improved energy efficiency is an important way to reduce energy use, and thereby $\mathrm{CO} 2$ emissions, and to overcome the climate change problem. We discussed state of the art methods for the technical and economic feasibility in the implementation of renewable energy sources, as well as the possibility of their combined use and substitution in the first part of this review. In the latter part we discussed energy efficiency technologies. Energy efficiency for electricity networks can be considered in different stages, such as power generation, transmission, distribution and consumption. For this purpose, different energy efficiency technologies are available, including electric vehicles, combined heat and power, virtual power plants and smart grids. Each of these technologies were discussed in detailed and their performances compared.

Electric vehicles have the potential to be used for both power generation and storage. Given the fact that transportation is a main contributor to the problem of emissions, improving fuel efficiency with the adoption of electric vehicle technology on a large scale will enable greater energy savings and $\mathrm{CO} 2$ reductions. Advances in smart grid technology impact the large scale use of electric vehicles and enhance the efficiency of the technology. However, managing load and supply fluctuations is a challenge. Combined heat and power technologies provide substantial gains in efficiency. The technology offers an efficiency use of fuel by preventing the discarding energy as waste heat. A significant part of waste heat can be transformed into a product for heating buildings, adding to its economic value and improving energy efficiency.

A virtual power plant is a cluster of distributed energy resources controlled and managed by a central control unit, allowing for the possibility to control home appliances to optimize load reductions. It helps to combat the energy waste problem due to distance and transmission losses. The driving force for using renewable energy technologies are energy security, economic impacts, and $\mathrm{CO} 2$ emission reduction. The level of insecurity is reflected by the risk of supply disruption and the estimated costs of security itself. The emphases for the economic impacts are job creation, industrial innovation and balance of payment. Renewable energy technologies could enable countries with good solar or wind resources to implement these energy sources to meet their own domestic demand.

Moreover, the cost of importing fuels can affect economic growth. If these countries could reduce their balance of payment by producing their own renewable energy to replace their dependence on fossil fuels, they could expand their capacity for investment in other sectors. Renewable energy technologies could reduce carbon dioxide emissions by replacing fossil fuels in the power generation industry and transportation sector. Life-cycle $\mathrm{CO} 2$ emissions for renewable energy technologies are much lower than fossil fuels. This review of renewable energy generation and efficiency technologies has provided detailed and useful information that can be used in the decision making of different stakeholders in the rapidly developing market. 
Each technology has both advantages and disadvantages that vary by location, availability, the technological capability of producers, financial limitations and environmental considerations. Each municipality, region or country has different initial conditions that determine the energy mix that can be produced at the lowest cost while minimizing the harm done to the environment. Thus, there is no single solution to every energy need and problem, but rather an optimal location specific solution among a set of possible renewable solutions.

\section{Conclusion}

Significant steps should be taken to reduce all kinds of energy losses. In India about $23 \%$ of energy is lost during transmission and distribution. This can be curtailed by adopting certain measures. One should use energy knowing that today's wastage will be tomorrow's shortage. Let's nurture the nature so that we can have better future.

\section{References}

[1] Nabih Jaber, "Efficient Home Energy Management System,” IEEE Trans. Consumer Electron., 2014.
[2] M. M. Rahman, M. Kuzlu, and S. Rahman "Architecture of Web Services Interface for A Home Energy Management System," IEEE Trans. Consumer Electron., 2014.

[3] Bian, M. Pipattanasomporn, and S. Rahman, "Assessment of Communication Technologies for a Home Energy Management System," IEEE Trans. Consumer Electron. 2014.

[4] M. Kuzlu, M. Pipattanasomporn, and S. Rahman, "Hardware Demonstration of a Home Energy Management System for Demand Response Applications" IEEE Trans. Smart Grid, Vol. 3, No. 4, July 2013.

[5] Energy Management System for Demand Response Applications," IEEE Trans. Smart Grid, VOL. 3, NO. 4, July 2013.

[6] Jinsoo Han, Chang-Sic Choi, and Ilwoo Lee, "More Efficient Home Energy Management System Based on ZigBee Communication and Infrared Remote Controls" IEEE Trans. 2011

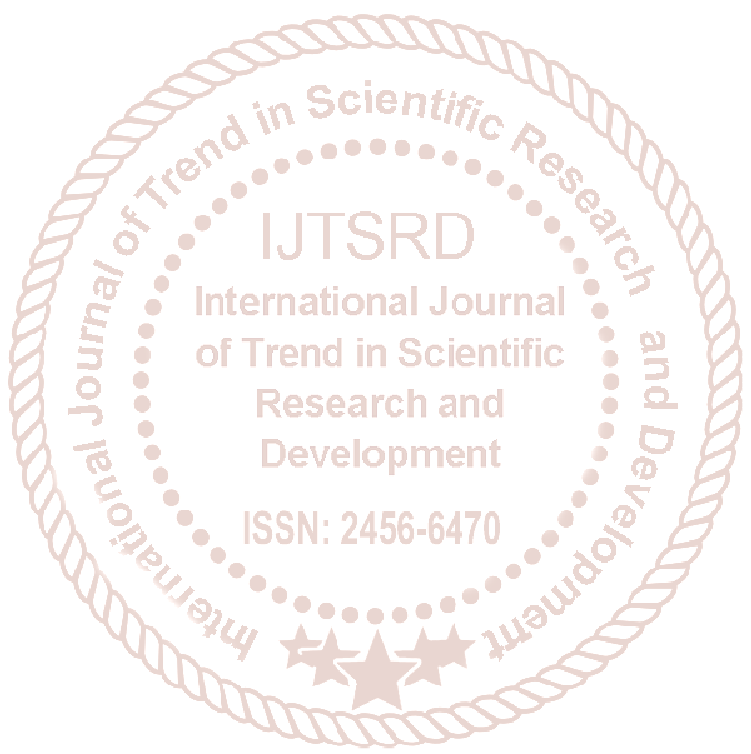

